\title{
Towards closure - considerations in tailings storage design
}

\author{
CS Hogg Coffey Geotechnics Pty Ltd, Australia
}

\begin{abstract}
This paper explores the relationship between geotechnical issues and drainage/water management in the design of tailings storages for closure, with an emphasis on high rainfall and tropical environments. Selection of the tailings system for a project will greatly influence the tailings geotechnical characteristics within the storage facility (i.e. tailings density and strength). Other influences include ore type, grind size etc. Options available include the use of high density thickened tailings or filtered tailings. Higher density and greater strength tailings should lead to reduced differential settlements, reduced risk of failure of tailings storage facility (TSF) cover drainage (water management) systems and hence better closure outcomes. Selection of the tailings system for the project can have other impacts on water management for the project, including water conservation (e.g. thickened or filtered tailings and greater return of water at the plant).
\end{abstract}

\section{Introduction}

This paper explores the relationship between geotechnical issues and drainage/water management in the design of tailings storages for closure, with an emphasis on high rainfall and tropical environments. Selection of the tailings system for a project will greatly influence the tailings geotechnical characteristics within the storage facility (i.e. tailings density and strength). The deposited tailings density and consolidation properties of the tailings will have a considerable impact on the strength profile within the tailings storage facility, both vertically and horizontally across the facility.

The paper presents typical in situ test results for different types of facilities, including Minerals and Energy Research Institute of Western Australia (MERIWA) project sites in Western Australia, a valley-type tailings storage for a gold mine in the tropics, and a valley-type TSF in Northern Australia containing thickened tailings. A geotechnical assessment is presented examining typical expected differential settlements for the various types of facilities. The paper then presents a discussion on the consequences of differential settlement and possible closure design concepts that can be used to manage expected settlement.

Finally the paper presents some possible alternative tailings storage strategies that are not sensitive to differential settlement and concludes with geotechnical issues that should be considered as part of closure planning.

\section{Terminology}

The type of storage facility, whether paddock, valley-type, side-hill or central thickened discharge, is largely determined by the type of terrain; however, the tailings disposal strategy can utilise various technologies, as listed below:

- Thickened tailings: a slurry where the solids content has been increased by liquid removal. Thickened slurries generally have a yield stress at the discharge point less than $200 \mathrm{~Pa}$. (eds Jewell \& Fourie 2006).

- Paste: thickened tailings having a high yield stress, typically above $200 \mathrm{~Pa}$. Pastes are mainly prepared for underground mine backfill operations (eds Jewell \& Fourie 2006).

- 'Cake' (Filter) is normally a partially saturated semi-solid produced by a filter (eds Jewell \& Fourie 2006). 
- Dry stacking: The description of the overall process of transporting, placing, and compacting filter 'cake' tailings to form an unsaturated tailings stack (Access Mining Consultants Ltd 2003).

\section{Aspects of geotechnics and water management}

\subsection{In situ testing - various sites}

In the 1990s the MERIWA project (Newson \& Fahey 1998) in Western Australia examined consolidation and evaporation of saline gold tailings in order to provide recommendations on the design, operation and rehabilitation of tailings storages. This study concentrated on paddock storage facilities at gold mines within Western Australia. The study revealed that the effect of evaporation on achieving higher tailings densities was pronounced (i.e. greater than relying on self-weight alone). It was noted that even without consolidation, deposited tailings will dry back from the deposited moisture content to a shrinkage limit that is characteristic of the tailings material (i.e. as revealed in the air drying test).

The data from the MERIWA project included cone penetrometer test (CPT) results. Of particular note was that generally, cone resistance near the embankment for saline gold tailings (low density thickened) was in the range 2 to $5 \mathrm{MPa}$ and near the decant $2 \mathrm{MPa}$ or less.

The author's experience with a valley-type tailings storage for a gold mine in the tropics (tropical valley TSF) which utilised low density tailings slurry deposition with beaches developed mostly from the main valley embankment to a decant area, provided a comparison with the MERIWA results. CPT testing was performed during the life of this facility, and indicated silty sands and cone resistance between 2 and $5 \mathrm{MPa}$ near the embankment (i.e. similar to the MERIWA project). In this instance, due to a positive TSF water balance, a large decant pond was located on the facility during the operational life of the facility, and testing was not performed in the decant area. Tailings strengths in this location within the TSF can be expected to be very low. A plot of the CPT results for this valley storage is presented in Figure 1.

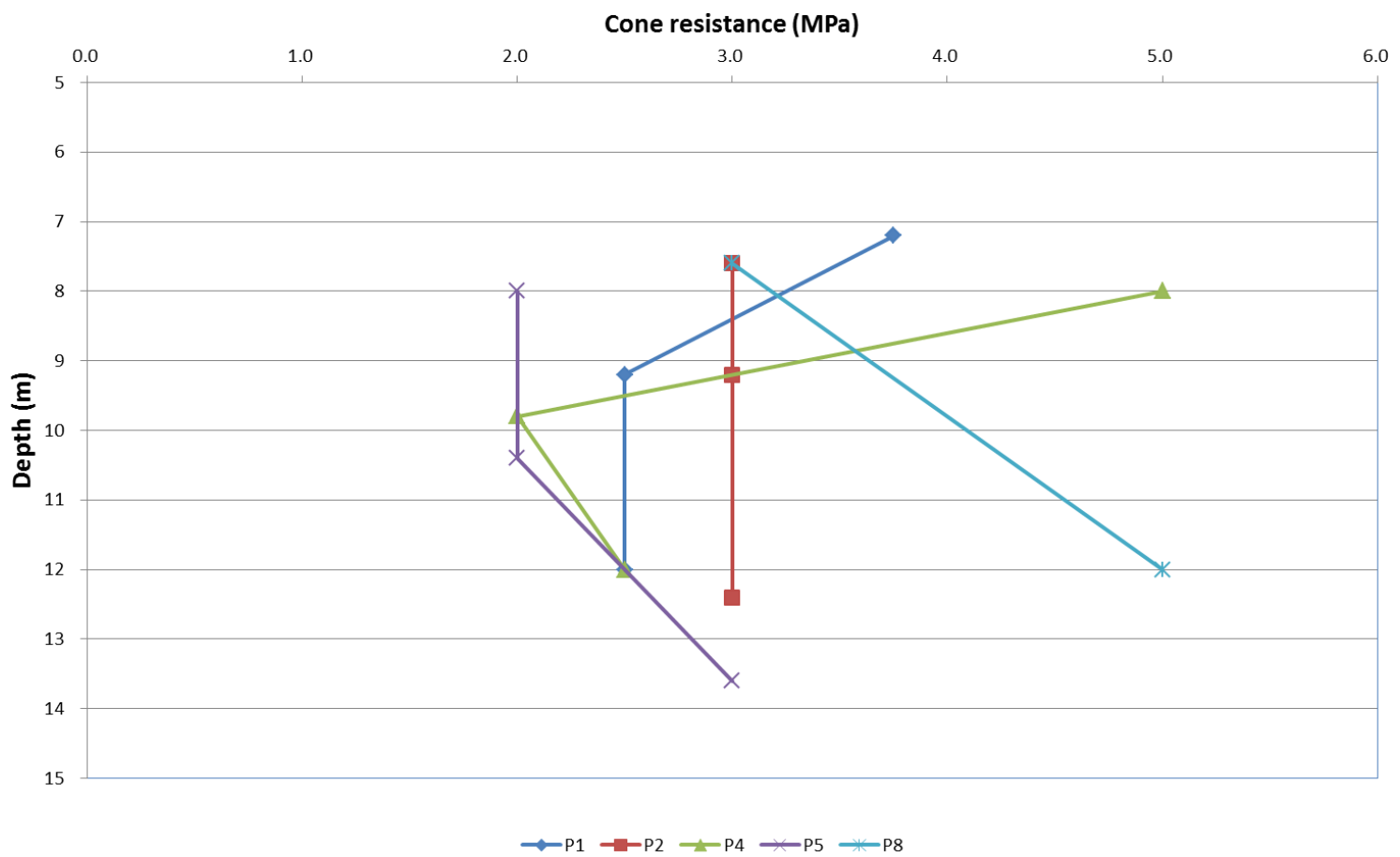

Figure 1 CPT results - interpreted cone resistance versus depth — 'tropical valley' TSF

The MERIWA results can also be compared with results from an investigation of a valley-type TSF in Northern Australia containing thickened tailings ('thickened tailings valley' TSF, Hogg 2010). The strength and friction ratios of the tailings were relatively uniform, typically indicating cone resistance of between 
2 and 4.7 MPa (Figure 2). There was an approximately $40 \%$ reduction in average cone resistance for CPT testing near the decant pond compared to those near the embankment.



Figure 2 CPT results - interpreted cone resistance versus depth — 'thickened tailings valley' TSF

The results of the CPT testing indicate relatively uniform strength profiles across the beach areas when compared with the MERIWA results, with only minor reduction in strength away from the main embankment towards the centre of the TSF. This may be expected for a thickened tailings storage where there is little segregation of the tailings. The implications of this are that there is a reduced likelihood of large differential settlement on these types of facilities when compared to conventional slurry systems; however, this depends on operating conditions such as filling rate (i.e. rate of tailings rise).

\subsection{Geotechnical analysis}

The following section provides a geotechnical analysis of typical CPT results in order to assess the impact of tailings beach settlement on closure. The settlement following loading with a mine waste cover is assessed in order to explore covering of thickened and low density thickened (unthickened) TSFs.

The estimation of settlement is usually based on a 1D constrained Modulus. The correlation between CPT results has been performed by a number of researchers. The correlations produced by Mitchell and Gardner (after Sanglerat, cited in Lunne et al. 1997) and correlations in Mayne (cited in Robertson 2009) have been used in the analyses below (Table 1). The main advance in these estimation of settlement techniques is that the more recent modelling techniques use normalised cone resistance, where the correlations from earlier studies did not. The normalisation of the cone resistance allows for the increase of cone resistance with depth due to increased stress.

$$
\text { Settlement, } S=(\Delta P / M) \times H
$$

where:

$$
\begin{aligned}
M & =1 D \text { Modulus }=1 / m_{v} . \\
\Delta P & =\text { loading of cover. } \\
H & =\text { tailings thickness. } \\
m_{v} & =\text { coefficient of compressibility. }
\end{aligned}
$$


The estimation of a 1D Modulus from undrained penetration test results, especially when based on empirical correlations, is liable to serious error (Lunne et al. 1997). Nevertheless the models are useful in estimating the likely magnitude of settlement of mine waste covers in closure studies. The estimates of settlement and differential settlement are given below for two different correlations, and a range of tailings depths and cone resistances (refer Table 1). The loading applied to the tailings is from a $2 \mathrm{~m}$ nominal thick mine waste cover. Differential settlement can be assessed based on a change of grade, due to potential settlement. In this case over $100 \mathrm{~m}$, which is an order of magnitude distance on a TSF. The results are summarised in Table 1 and plotted on Figures 3 and 4.

Table 1 Analysis results

\begin{tabular}{|c|c|c|c|c|c|c|}
\hline $\begin{array}{c}\text { Average } \\
\text { qc thru } \\
\text { profile } \\
\text { (Mpa) }\end{array}$ & $m_{v}\left(m^{2} / N\right)$ & $H(m)$ & $\Delta \mathrm{P}(\mathrm{Pa})$ & $S(m)$ & $\begin{array}{c}\text { Grade } \\
\text { (over } \\
100 \mathrm{~m} \text { ) }\end{array}$ & Comments \\
\hline 5 & $5.0 \mathrm{E}-08$ & 30 & 36,000 & 0.054 & & \multirow[t]{6}{*}{ Thickened storage-beach settlement } \\
\hline 2 & $1.67 \mathrm{E}-07$ & 30 & 36,000 & 0.18 & $0.13 \%$ & \\
\hline 5 & $5.0 \mathrm{E}-08$ & 20 & 36,000 & 0.036 & & \\
\hline 2 & $1.67 E-07$ & 20 & 36,000 & 0.12 & $0.08 \%$ & \\
\hline 5 & $5.0 \mathrm{E}-08$ & 10 & 36,000 & 0.018 & & \\
\hline 2 & 1.67E-07 & 10 & 36,000 & 0.06 & $0.04 \%$ & \\
\hline 2 & $1.67 \mathrm{E}-07$ & 30 & 36,000 & 0.18 & & \multirow[t]{6}{*}{$\begin{array}{c}\text { Unthickened storage-settlement near } \\
\text { decant }\end{array}$} \\
\hline 1 & $1.0 \mathrm{E}-06$ & 30 & 36,000 & 1.08 & $0.90 \%$ & \\
\hline 2 & $1.67 \mathrm{E}-07$ & 20 & 36,000 & 0.12 & & \\
\hline 1 & $1.0 \mathrm{E}-06$ & 20 & 36,000 & 0.72 & $0.60 \%$ & \\
\hline 2 & $1.67 \mathrm{E}-07$ & 10 & 36,000 & 0.06 & & \\
\hline 1 & $1.0 \mathrm{E}-06$ & 10 & 36,000 & 0.36 & $0.30 \%$ & \\
\hline
\end{tabular}

Mitchell and Gardner 1975 (adapted from Sanglerat 1972, cited in Lunne et al. 1997); $m_{v}=a_{m} \times q_{c} ; q_{c}>2 M p a 3<a_{m}<6 ; q_{c}<2 M p a 1<a_{m}<3$

\begin{tabular}{ccccccc}
\hline $\begin{array}{c}\text { Average qc } \\
\text { thru profile } \\
(\mathrm{Mpa})\end{array}$ & $\begin{array}{c}\mathrm{m}_{\mathrm{v}} \\
\left(\mathrm{m}^{2} / \mathrm{N}\right)\end{array}$ & $\mathbf{H}(\mathbf{m})$ & $\mathbf{\Delta P}(\mathrm{Pa})$ & $\mathbf{S}(\mathbf{m})$ & $\begin{array}{c}\text { Grade } \\
(\text { over } \\
\mathbf{1 0 0 m})\end{array}$ & Comments \\
\hline 5 & $4 \mathrm{E}-08$ & 30 & 36,000 & 0.0432 & & Thickened storage-beach settlement \\
\hline 2 & $1.67 \mathrm{E}-07$ & 30 & 36,000 & 0.18 & $0.14 \%$ & \\
\hline 5 & $4 \mathrm{E}-08$ & 20 & 36,000 & 0.0288 & & \\
\hline 2 & $1.67 \mathrm{E}-07$ & 20 & 36,000 & 0.12 & $0.09 \%$ & \\
\hline 5 & $4 \mathrm{E}-08$ & 10 & 36,000 & 0.0144 & & \\
\hline 2 & $1.67 \mathrm{E}-07$ & 10 & 36,000 & 0.06 & $0.05 \%$ & \\
\hline
\end{tabular}

Mayne 2007 (cited in Robertson 2009); $M=K_{M P a} M=1 / m_{V}$

Note: $\mathrm{mv}$ from consolidation testing under taken at the time of the original TSF design was approximately $3 \mathrm{~m}^{2} / \mathrm{MN}$ 
Plots of differential settlement versus tailings depth are provided below in Figures 3 and 4 .

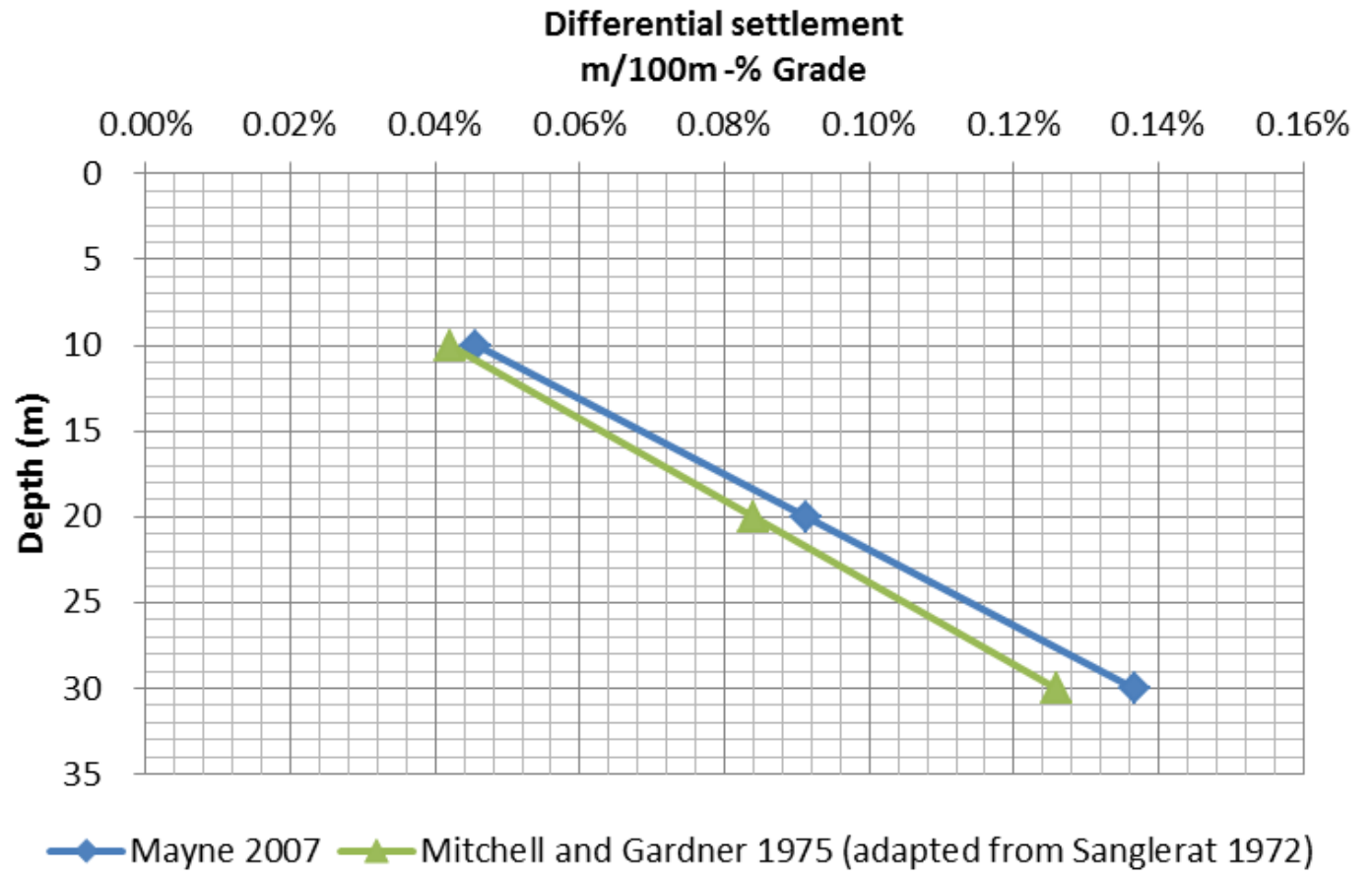

Figure 3 Analysis results - plots of differential settlement (\% grade) versus depth - thickened storage. Mitchell and Gardner (after Sanglerat, cited in Lunne et al. 1997) and Mayne (cited in Robertson 2009)

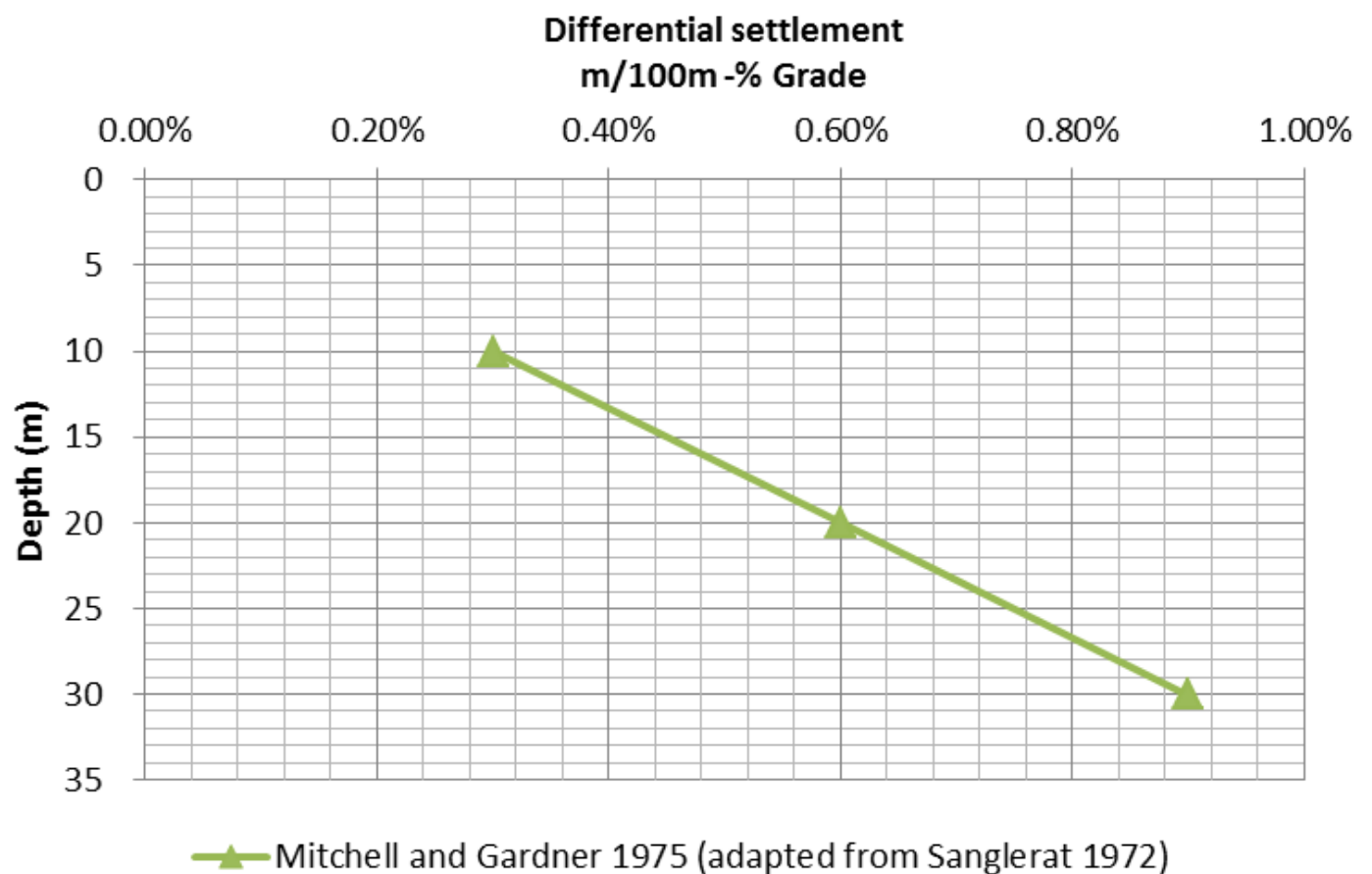

Figure 4 Analysis results - plots of differential settlement (\% grade) versus depth - unthickened storage near decant. Mitchell and Gardner (after Sanglerat, cited in Lunne et al. 1997)

The results of the settlement analyses indicated that for high strength tailings (i.e. normalised cone resistances between 2 and $5 \mathrm{MPa}$ ), the differential settlements can be expected to be less than $0.1 \%$ (i.e. manageable). The differential settlements for low strength tailings can be much higher and such differential settlements will be difficult to manage in design, hence greater time is required to allow consolidation in such instances. 


\subsection{Implications for design}

The differential settlement of the tailings has implications for drainage design of TSF covers. Differential settlement leading to significant ponding on the cap should be avoided particularly for tailings with a potential for geochemical activity (i.e. acid mine drainage (AMD) issues). The likelihood of significant ponding on the TSF cap is considered lower if the tailings have high density and greater strength.

Allowance in the final capping design should be made for grade adjustment of the cap surface to allow for differential settlement. Differential settlement of around $0.1 \%$ (refer to plots above) would not have a detrimental effect on the function of internal drains on a TSF.

In the case of the valley-type TSF in Northern Australia mentioned above, the cap will have a grade of $2 \%$ and any 'internal' drains should have a minimum grade of $0.5 \%$ so as to maintain a consistent fall.

Storage settlement characteristics of valley storage should be taken into account when generating design concepts for closure. With due consideration of differential settlement, valley tailings storages lend themselves to the following closure design concepts:

- Partial wet cover option - Segregation of tailings within the facility. Capping of sandy tailings near the embankment with a permanent water pond away from embankment. The water pond level is controlled by the level of the outlet spillway and a 'positive' water balance is a requirement. Adequate for tropical environments and low-density tailings slurry systems. Allowance for settlement should not be required in capping design.

- Store and release cover - domed cover on the top surface with due allowance for tailings differential settlement and top surface drainage in the cover design. Adequate for monsoonal and semi-arid environments.

- Water cover - Tailings settlement less of an issue with this option. Concept suitable for tropical and high rainfall environments (i.e. neutral or positive water balance environments).

The concepts below assume potential for geochemical activity of the tailings (i.e. AMD issues). The concepts are shown in the schematics in Figure 5.

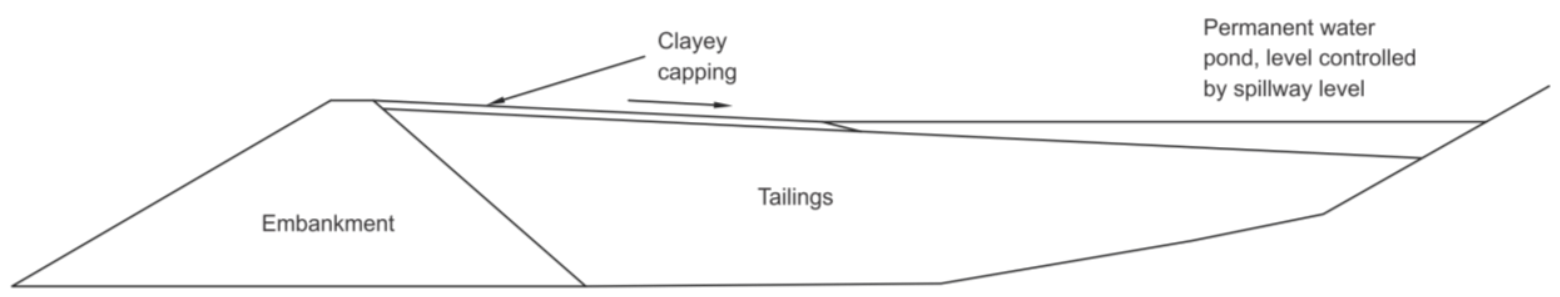

Design concept - partial wet cover option

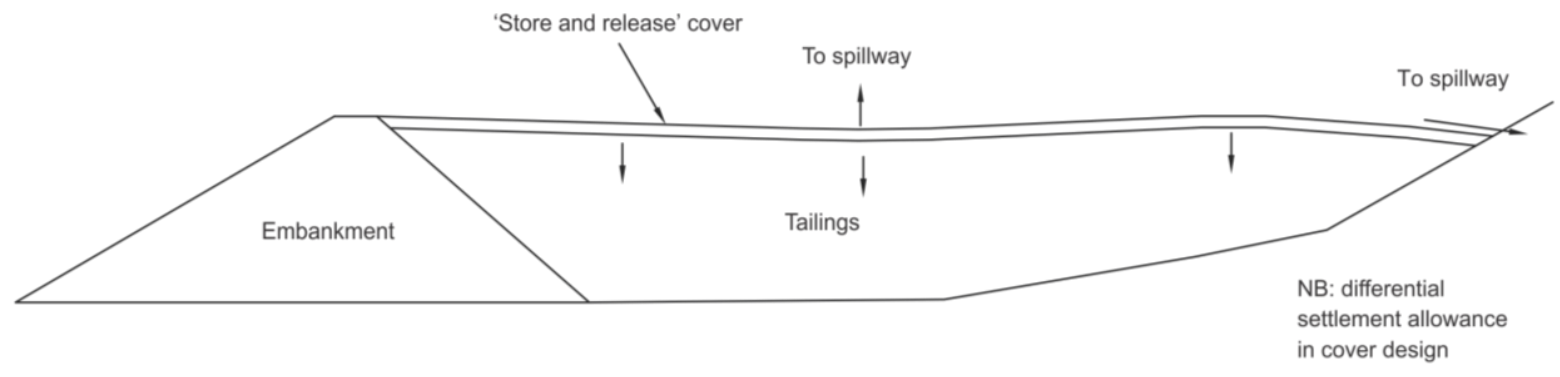

Design concept - domed store and release cover

Figure 5 Typical design concepts - TSF closure 


\section{$4 \quad$ Alternative strategies}

\subsection{In-pit storage}

If mined-out voids are available, in-pit tailings storage can be considered. The characteristics of an in-pit storage in a tropical or high rainfall environment are likely to be:

- Subaqueous tailings deposition resulting in low in situ densities.

- Wet cover at closure.

- Greater than $100 \%$ water return: with related treatment and disposal of excess water.

In-pit TSFs in tropical environments have unique issues; however, they have several closure advantages as listed below:

- Water cover 'excludes' oxygen from geochemically active tailings.

- No cover construction, hence saving closure costs. However, a downstream wetland will probably be required.

- TSF water balance critical. Special allowance for drought needs to be made to ensure reactive tailings are not exposed.

It should also be noted that there are numerous examples of successfully rehabilitated in-pit TSFs in the semi-arid environment of the goldfields in Western Australia (i.e. where the facilities have been successfully covered with a mine waste cover). Specific characteristics of these facilities are:

- Gold tailings with good consolidation properties and relatively low filling rates (due to the underground mining phase of the project).

- Use of surface water decant systems and under-drainage systems.

- Tailings have no AMD issues.

\subsection{Dry stacking}

The tailings are de-watered using a filter system and are delivered to the tailings storage site via a truck operation or utilising conveyor systems. De-watering the tailings in the plant to produce filtered tailings, at around $80 \%$ solids, reduces water consumption for the project. Another advantage of filtered tailings is the placement of tailings at higher density, allowing smaller disposal footprint areas when compared with more traditional options.

Dry stacking has been attempted at relatively 'small' mines and there are likely scale-up issues that would need to be addressed. In addition, in tropical environments where the site often has a positive water balance, water savings through 'dry stacking' are not required.

\section{Conclusion}

When designing tailings storage facilities for closure, issues of tailings strength and density, differential settlement and impact on water management (drainage) at closure should be considered. The results of analyses presented in Section 3 indicate that differential settlements from thickened tailings should be more readily managed than possible differential settlements from ('unthickened') low density thickened tailings deposits.

Adequate geotechnical characterisation of the tailings within the facility should be conducted during the life of the facility. This data collection will prove invaluable when conducting closure planning and design. 
The following should be considered:

- Use of CPT testing as an efficient and effective method of collecting data on consolidation characteristics of tailings in moderate risk projects (i.e. most closure studies).

- In situ testing will need to be used in concert with laboratory test work (i.e. consolidation testing).

- In high risk projects a detailed interpretation of CPT together with laboratory testing and numerical modelling would be appropriate (i.e. closure studies where structures are built on top of the facility etc.).

- Periodic sampling and testing during the life of the TSF to form a database of parameters provides an advantage when planning for closure.

Alternatives should be considered in the initial planning of a project. For instance, high density tailings thickening or dry stacking should be considered as tailings disposal options where there is a lack of available water resources or such resources are expensive, or seepage is a particular environmental issue. Dry stacking could be considered as a tailings disposal option where the mining project is constrained by available land or where terrain or borrow/fill sources make construction of conventional tailings disposal facilities expensive.

\section{Acknowledgement}

Thanks to Clive Saunders of Coffey for the original proof reading of the paper.

\section{References}

Access Mining Consultants Ltd 2003, 'Examination of Revegetation Methodologies for Dry Stack Tailings in Northern Environments', Mining Environmental Research Group, Government of Yukon, pp. 3-4.

Hogg CS 2010, 'Some geotechnical aspects of closure: case study of a thickened tailings valley storage in Western Australia', Mine Waste 2010, Perth.

Jewell, RJ \& Fourie, AB (eds) 2006, Paste and Thickened Tailings - A Guide, 2nd edition, Australian Centre for Geomechanics, Perth, pp. 6-7, pp. 239-241.

Lunne T, Robertson PK \& Powell, JJM 1997, 'Cone Penetration Testing in Geotechnical Practice', E \& FN Spon.

Newson TA \& Fahey M 1998, MERIWA Project No. M241 (1998) Saline Tailings Disposal and Decommissioning, TA Newson \& $M$ Fahey (eds), Australian Centre for Geomechanics, Perth.

Robertson, PK 2009, Interpretation of cone penetration tests - a unified approach, NRC Research Press, cgj.nrc.ca 